\title{
PENGENDALIAN HAMA PENTING TANAMAN PADI MENGGUNAKAN JAMUR Beauveria bassiana Bals
}

\author{
Sopialena ${ }^{1}$, Abdul Sahid ${ }^{2}$, Nike Stella Trifena Rugian ${ }^{3}$ \\ 1,2,3 Agroekoteknologi, Fakultas Pertanian, Universitas Mulawarman, Jalan Pasir \\ Balengkong \\ Kampus Gunung Kelua, Universitas Mulawarman, Samarinda, Kalimantan Timur, \\ Indonesia. \\ E-Mail: sopialena88@gmail.com
}

\begin{abstract}
ABSTRAK
Pengendalian Hama Penting Tanaman Padi Menggunakan Jamur Beauveria bassiana Bals. Jamur entomopatogen Beauveria bassiana Bals sangat potensial mengendalikan berbagai serangga hama, penelitian ini dilakukan untuk pengendalian hama penting tanaman padi dengan menggunakan jamur Beauveria bassiana Bals di Desa Sebuntal Kecamatan Marang Kayu Kabupaten Kutai Kartanegara. Adapun tujuan penelitian adalah mengidentifikasi hama serangga penting yang terdapat di lahan sawah Desa Sebuntal Kecamatan Marangkayu Kabupaten Kutai Kartanegara Provinsi Kalimantan Timur dan untuk mengetahui konsentrasi Beauveria bassiana Bals.yang efektif dalam mengendalikan intensitas serangan hama penting pada tanaman padi sawah (Oryza sativa L.). Penelitian disusun dalam Rancangan Acak Kelompok (RAK), terdiri dari lima perlakuan yaitu dengan konsentrasi $\mathrm{B} 0=$ (kontrol), B1 $=5 \mathrm{ml} /$ liter, B2 $=10 \mathrm{ml} / \mathrm{liter}, \mathrm{B} 3=15$ $\mathrm{ml} /$ liter, dan B4 = $20 \mathrm{ml} /$ liter. masing-masing perlakuan diulang 4 kali, Perlakuan Beauveria bassiana diaplikasikan pada umur 2 minggu setelah tanam, 3 minggu setelah tanam, 4 minggu setelah tanam, 5 minggu setelah tanam, 6 minggu setelah tanam, 7 minggu setelah tanam, 8 minggu setelah tanam, 9 minggu setelah tanam, 10 minggu setelah tanam, 11 minggu setelah tanam dan 12 minggu setelah tanam. Hasil penelitian menunjukkan bahwa ada 3 (tiga) hama serangga penting yang teridentifikasi yang terdapat di lahan sawah Desa Sebuntal Kecamatan Marangkayu Kabupaten Kutai Kartanegara Provinsi Kalimantan Timur, yaitu: hama Putih Palsu (Chanaphalocrosis medinalis) pada fase vegetatif, penggerek batang (tryporiza sp.) pada fase generatif (beluk) dan hama walang sangit (Leptocorixa acuta) pada fase generatif dan konsentrasi yang efektif dalam mengendalikan hama pada tanaman padi (Oryza sativa L.) adalah 15 $\mathrm{ml} / \mathrm{L}$.
\end{abstract}

Kata kunci : Beauveria bassiana Bals, Hama, Padi.

\begin{abstract}
Important Pest Control Of Rice Plants Using The Fungus Beauveria bassiana Bals. Beauveria bassiana Bals entomopatogen fungus is very potential controlling various insect pests, this research was conducted to control important pests of rice plants using fungi of the Beauveria bassiana Bals in Sebuntal Village, Marang Kayu District, Kutai Kartanegara Regency. The purpose of the research is to identify important insect pests found in the lowland areas of Sebuntal Village, Marangkayu District, Kutai Kartanegara Regency, East Kalimantan Province and to determine the concentration of Beauveria bassiana Bals in controlling the pest on rice plants (Oryza sativa L.). The research used a Randomized Block Design (RBD), consisting of five treatments namely BO = (control), B1 =5 ml /liter, B2 = $10 \mathrm{ml} /$ liter, B3 = $15 \mathrm{ml} /$ liter, and $B 4=20 \mathrm{ml} /$ liter. Each treatment was repeated 4 times, Beauveria bassiana treatment was applied at the age of 2 weeks after planting, 3 weeks after planting, 4 weeks after planting, 5 weeks after planting, 6 weeks after planting, 7 weeks after planting, 8 weeks after planting, 9 weeks after planting, 10 weeks after planting, 11 weeks after planting and 12 weeks after planting. The results showed that there were 3 (three) Important insect pests identified in the paddy fields of Sebuntal Village, Marangkayu District, Kutai Kartanegara Regency, East Kalimantan Province, namely: Fake White pests (Chanaphalocrosis medinalis) in the vegetative phase, stem borer (Tryporiza sp.) in the generative phase (outs) and pest pest Sangit
\end{abstract}


(Leptocorixa acuta) in the generative phase and the effective concentration in controlling pests in rice plants (Oryza sativa L.) is $15 \mathrm{ml} / \mathrm{L}$.

Key words : Beauveria bassisna Bals, Pests, Rice.

\section{PENDAHULUAN}

Padi (O. sativa) merupakan salah satu komuditas pangan utama di Indonesia, komsumsi beras nasional pada tahun 2017 mencapai 29,13 juta ton atau 111,58 kilogram per kapita per tahun (Kementerian Pertanian, 2014). Produksi tanaman padi di daerah Kalimantan Timur pada tahun 2011 mencapai 346.530 ton akan tetapi pada tahun 2015 mengalami penurunan hasil produksi sebesar 16.531 ton sehingga produksi hanya mencapai 329.999 ton saja (Dinas Tanaman Pangan dan Hortikultura, 2015). Salah satu faktor yang mempengaruhi penurunan produksi tanaman padi adalah oraganisme pengganggu tanaman atau yang biasa disebut OPT. Hama serangga merupakan salah satu OPT pada tanaman padi. Hama serangga merupakan salah satu organisme pengganggu tanaman yang dapat menurunkan hasil produksi padi (Dinas Tanaman Pangan dan Hortikultura, 2015). Pengendalian hama yang biasa dilakukan oleh petani adalah dengan menggunakan pestisida kimia namun penggunaan pestisida kimia ini ternyata mempunyai dampak negatif bagi ekosistem (Kartohardjono, 2011). Dampak negatif yang diakibatkan oleh penggunaan pestisida kimia diantaranya adalah pencemaran lingkungan bagi tanah, air bahkan produk tanaman tersebut dapat terkandung residu atau sisa bahan kimia pestisida yang dapat berakibat buruk bagi kesehatan manusia dalam jangka waktu lama. Dampak negatif penggunaan pestisida kimia bagi hama tersebut yaitu dapat menyebabkan resurjensi hama yaitu suatu fenomena meningkatnya populasi hama tertentu. Penggunaan pestisida kimia juga dapat menyebabkan resitensi hama atau menurunnya kepekaan hama terhadap pestisida mengakibatkan hama menjadi kebal, selain itu penggunaan pestisida kimia juga dapat membunuh musuh alami sehingga penggunaan pestisida kimia sudah tidak menjadi efektif lagi (Parsa dkk., 2017).

Untuk mengurangi penggunaan pestisida kimia sebagai upaya pengendalian serangan hama maka dapat dilakukan dengan cara pengendalian hayati yang lebih ramah lingkungan. Pengendalian hayati adalah pemanfaatan mikroorganisme dengan tujuan mengendalikan populasi Organisme Pengganggu Tanaman (OPT). Pengendalian hayati adalah memanfaatkan agen hayati yang bersifat antagonis pada organisme pengganggu tanaman atau juga biasa disebut musuh alami hama (Indiati dan Marwoto, 2017). Keuntungan dari pengendalian hayati dengan menggunakan musuh alami adalah selektif terhadap hama sasaran, tidak mengakibatkan resistensi hama, tidak mengakibatkan resurjensi hama dan tidak mengakibatkan residu pada tanaman maupun lingkungan (Muhammad, 2015). Salah satu musuh alami hama serangga adalah jamur Beauveria bassiana Bals (Usyati dkk., 2018). B. bassiana adalah jamur entomopatogen yang artinya cendawan tersebut bersifat parasit yang mengakibatkan sakit pada serangga. $B$. bassiana merupakan salah satu jamur yang menghasilkan enzim kitinase, esterase, lipase dan protease yang berperan menghacurkan kulit luar serangga atau yang disebut kutikula serangga (Widariyanto dkk., 2017). Oleh sebab itu jamur $B$. bassiana dapat dijadikan sebagai musuh alami hama serangga dalam mengendalikan populasi hama serangga, sehingga diharapkan 
dapat menekan kerugian produksi tanaman yang disebabkan oleh hama serangga.

\section{METODA PENELITIAN}

\subsection{Tempat dan Waktu}

Penelitian dilaksanakan selama 4 bulan dilakukan pada bulanJanuari sampai dengan Juli-November 2018 terhitung dari persiapan lahan sampai dengan pengambilan data terakhir. Penelitian ini dilakukan di Desa Sebuntal, Kecamatan Marang Kayu, Kabupaten Kutai Kartaegara.

\subsection{Bahan dan Alat}

Bahan yang digunakan dalam penelitian adalah jamur (Beauveria bassiana Bals.), guladan air. Alat yang digunakan dalam penelitian adalah kayu (untuk membuat petak Ubinan), kertas, spidol, pita, meteran, penggaris, tali rapia, gelas ukur dan knapsack (semprotan).

\subsection{Rancangan Penelitian}

Penelitian ini menggunakan terdiri dari 3 tahapan yaitu: penanaman tanaman padi, identifikasi hama serangga tanaman padi, dan perlakuan jamur entomopatogen Beauveria bassiana Bals beda konsentrasi dengan menggunakan (RAK) terdiri dari 5 perlakuan dan 4ulangan, B0 = (kontrol); B1 = $5 \mathrm{ml} /$ liter; $\mathrm{B} 2=10$ $\mathrm{ml} /$ liter,; B3 $=15 \mathrm{ml} /$ liter; danB4 = $20 \mathrm{ml} / \mathrm{liter}$.

\subsection{Identifikasi Hama Serangga di Lahan Persawahan}

Identifikasi dilakukan dengan melihat gejala serangan hama serangga dan melihat morfologi hama seranggga.

\subsection{Perlakuan Jamur Beauveria bassiana Bals \\ Pemberian Jamur Beauveria} bassiana Bals dengan carajamur Beauveria bassiana Bals. yang dicampur gula dengan perbandingan 1:3 lalu disemprotkan menggunakan knapsack penyemprotan dengan konsentrasi $\mathrm{B} 0=($ kontrol $), \mathrm{B} 1=5$ $\mathrm{ml} /$ liter, B2 $=10 \mathrm{ml} /$ liter, B3 $=15$ $\mathrm{ml} /$ liter, dan $\mathrm{B} 4=20 \mathrm{ml} / \mathrm{liter}$. Pengamatan dilakukan pada umur 7 minggu setelah tanam, 8 minggu setelah tanam, 9 minggu setelah tanam, 10 minggu setelah tanam, 11 minggu setelah tanam dan 12 minggu setelah tanam.

\subsection{Pengambilan Data}

Data yang diambil dari penelitian ini adalah: IIdentifikasi HamaIdentifikas hama dilakukan dengan mengamati langsung hama penting yang menyerang tanaman sampel dan menentukan jenis hama tersebut. hama yang termasuk hama penting ialah yang menunjukan gejala kerusakan mutlak (atau yang dianggap mutlak); Intensitas Serangan HamaPenilaian terhadap kerusakan tanaman dilakukan berdasarkan gejala serangan hama yang sifatnya sangat beragam. Kerusakan tanaman oleh serangan hama dapat berupa kerusakan mutlak (atau yang dianggap mutlak) dan tidak mutlak; Kerusakan Mutlak Untuk menilai serangan hama yang menyebkan kerusakan mutlak atau dianggap mutlak digunakan rumus

$$
I=\frac{a}{a+b} \times 100 \%
$$




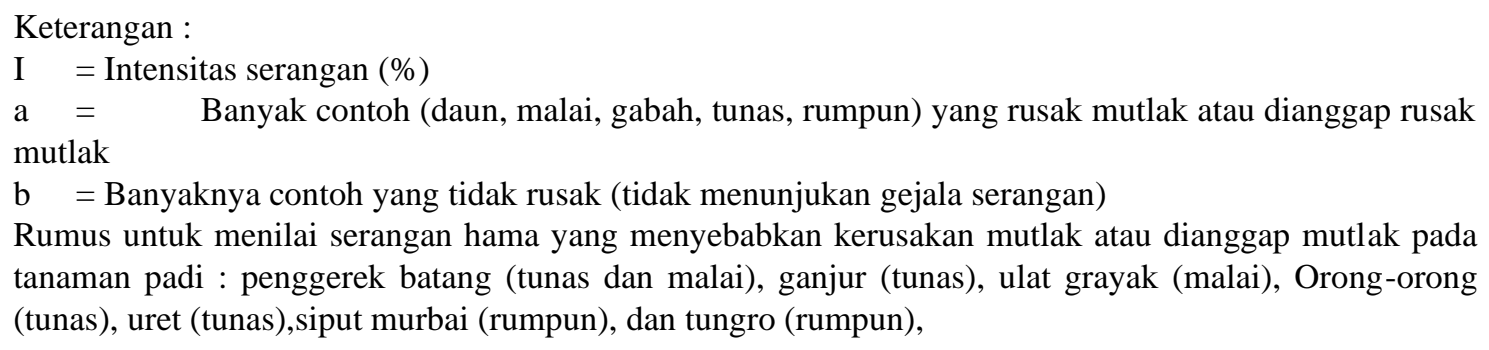

Kerusakan tidak mutlak

Untuk menilai serangan hama yang tidak menimbulkan kerusakan mutlak digunakan rumus:

$$
\mathrm{I}=\frac{\sum(\text { ni } \mathrm{X} \mathrm{vi})}{\mathrm{ZX} \mathrm{N}} \times 100 \%
$$

Keterangan :

$\mathrm{I}=$ Intensitas serangan $(\%)$

$\mathrm{n}_{\mathrm{i}}=$ Jumlah tanaman atau bagian tanaman contoh dengan skala kerusakan $\mathrm{v}_{\mathrm{i}}$

$\mathrm{v}_{\mathrm{i}}=$ Nilai skala kerusakan contoh ke-i

$\mathrm{N}$ = Jumlah tanaman atau bagian tanaman contoh yang diamati

$\mathrm{Z}=$ Nilai skala kerusakan tertinggi

Rumus untuk menilai serangan hama tidak mutlak padi : Walang sangit (malai), dan wereng batang coklat (rumpun).

2.7.

\section{Analisis data}

Data dianalisis dengan uji $\mathrm{F}$, dan bila berbeda nyata dilanjutkan dengan analisis Beda NyataTerkecil pada taraf $5 \%$.

\section{HASIL PENELITIAN DAN PEMBAHASAN}

Dari penelitian yang dilakukan didapati hasil bahwa terdapat beberapa hama serangga utama yang menyerang tanama padi, yaitu: hama Putih Palsu (Chanaphalocrosis medinalis Guen.) pada fase vegetatif, Penggerek Batang (Tryporiza sp.) pada fase generatif dan hama walang sangit (Leptocorixa acuta) pada fase generatif.

\section{Hama Putih Palsu (Chanaphalocrosis} medinalis Guen.) 


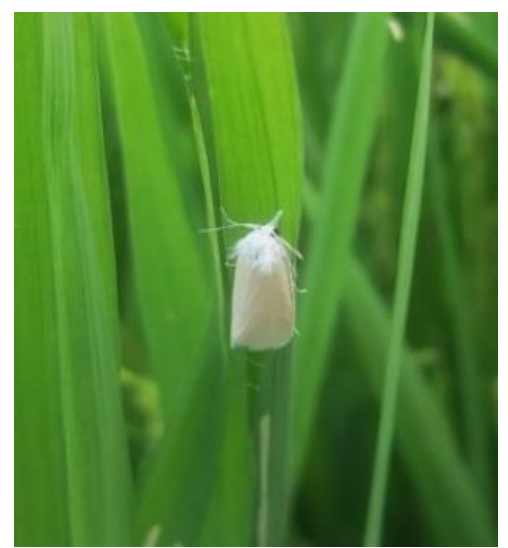

Gambar 1. Imago hama putih palsu (C. medinalis)

Hama putih palsu (C. medinalis) ditemukan pada fase vegetatif yaitu pada minggu ke 7, 8, 9 dan 10 mst. Ciri gejala serangan hama putih palsu yaitu, daun padi bergulung dan terdapat garis putih dan garis putih tersebut sejajar dengan ibu tulang daun serta didalam garis putih tersebut terdapat hama putih palsu $(C$. medinalis).

\section{Hama Penggerek Batang (Tryporiza sp.) \\ Penggerek Batang (Tryporiza sp.) adalah hama yang menimbulkan kerusakan dan menurunkan hasil panen secara nyata. Dari hasil pengamatan didapati hama penggerek batang menyerang pada fase generatif yaitu pada saat padi berumur $11 \mathrm{mst}$.}

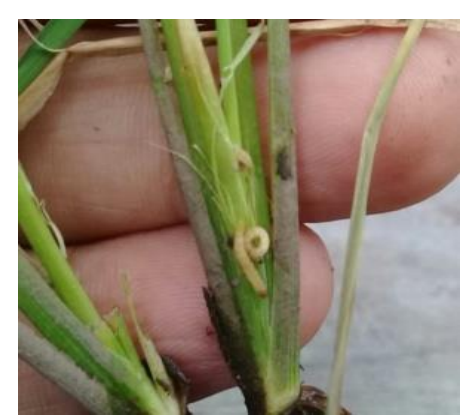

Gambar 2. Penggerek Batang (Tryporiza sp.)

Gejala serangan ini adalah gejala serangan beluk. Gejala serangan beluk ditandai dengan larva Penggerek Batang memakan pangkal batang malai tanaman padi. Malai akan mati berwarna abu-abu dan bulirnya kosong/hampa. Malai mudah dicabut dan pada pangkal batang terdapat bekas gerekan larva Penggerek Batang.

\begin{abstract}
Hama Walang Sangit (Leptocorixa acuta Thunb)

Walang Sangit (Leptocorixa acuta Thunb) menyerang tanaman pada fase generatif awal, karena pada fase ini bulir tanaman masih berupa cairan seperti susu yang dengan mudah dapat dihisap oleh stylet (alat mulut) walang sangit yang bertipe penusuk dan penghisap.
\end{abstract}




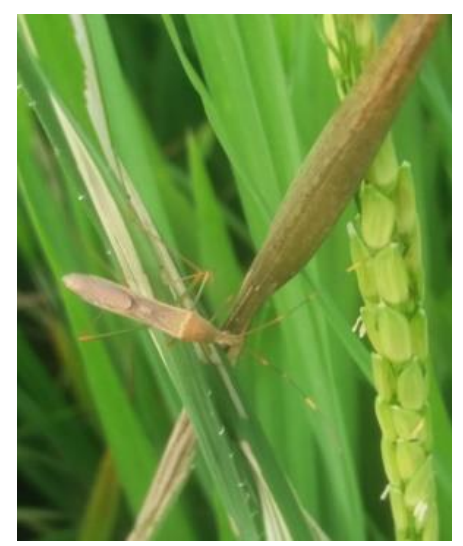

Gambar 3. Hama Walang Sangit (Leptocorixa acuta Thunb.)

Pengamatan yang dilakukan didapati gejala serangan hama Walang Sangit yaitu, bulir padi menjadi hampa atau kosong dikarenakan pada saat fase masak susu, walang sangit mengisap cairan tangkai bunga dan bulir padi akibatnya bulir padi menjadi tidak sempurna dan menyebabkan bulir padi menjadi hampa.

Hasil pengamatan yang dilakukan didapat gejala serangan hama walang sangit yaitu, bulir padi menjadi hampa atau kosong karena pada saat fase masak susu, walang sangit mengisap cairan bunga dan bulir padi akibatnya bulir padi menjadi tidak sempurna dan menyebabkan bulir padi menjadi hampa.

\section{Intensitas Serangan Hama Serangga}

Intensitas serangan Hama Putih Palsu (Chanaphalocrosis medinalis Guen)

Tabel 1. Intensitas serangan (\%) hama putih palsu (C. medinalis) pada tanaman Padi (O. sativa)

\begin{tabular}{|c|c|c|c|c|}
\hline \multirow{2}{*}{ Perlakuan } & \multicolumn{4}{|c|}{ Umur tanaman padi } \\
\hline & $7 \mathrm{mst}$ & $8 \mathrm{mst}$ & $9 \mathrm{mst}$ & $10 \mathrm{mst}$ \\
\hline & \multicolumn{4}{|c|}{ 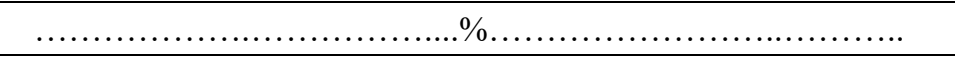 } \\
\hline B0 & $18.78 \mathrm{~d}$ & $20.47 \mathrm{c}$ & $19.73 \mathrm{c}$ & $17.58 \mathrm{~d}$ \\
\hline B1 & $17.91 \mathrm{c}$ & $19.12 \mathrm{~b}$ & $17.36 \mathrm{~b}$ & $16.65 \mathrm{c}$ \\
\hline $\mathrm{B} 2$ & $16.01 \mathrm{~b}$ & $18.37 \mathrm{~b}$ & $17.17 \mathrm{~b}$ & $16.18 \mathrm{c}$ \\
\hline B3 & $15.21 \mathrm{a}$ & $16.53 \mathrm{a}$ & $15.53 \mathrm{a}$ & $15.27 \mathrm{~b}$ \\
\hline B4 & $15.43 \mathrm{a}$ & $16.57 \mathrm{a}$ & $15.47 \mathrm{a}$ & $13.48 \mathrm{a}$ \\
\hline
\end{tabular}

Keterangan: Angka rerata yang diikuti oleh huruf yang sama pada tiap kolom menunjukkan tidak berbeda nyata menurut uji BNT pada taraf 5\% $(\mathrm{BNT}: 7 \mathrm{mst}=0,11,8 \mathrm{mst}=0,01,9 \mathrm{mst}=0,13$, dan 10 $\mathrm{mst}=0,15)$.

Hasil pengamatan menunjukkan bahwa tanaman padi varietas Mekongga yang diuji menggunakan kombinasi Jamur $B$. bassiana menyatakan berbeda sangat nyata. Hasil pengamatan rata-rata intensitas serangan hama utama pada daun tiap perlakuan dapat dilihat pada Tabel 1. Populasi hama putih palsu pada pengamatan $7 \mathrm{mst}, 8 \mathrm{mst}, 9 \mathrm{mst}$ dan 10 mst menunjukan hasil berbeda sangat nyata antara perlakuan, hasil pengamatan dilapangan menunjukan perbedaan antara perlakuan B0, B1, B2, B3 dan B4 terhadap intensitas serangan hama. Hasil pada perlakuan B0 (kontrol) menunjukan tingkat serangan yang tinggi hal ini disebebkan karena pada B0 tidak ada pengaplikasian Jamur B.bassiana, 
sehingga hama dengan mudah dapat menyerang tanaman dan hampir rata-rata pada perlakuan B1 dan B2 dilapangan tidak saling berbeda nyata terhadap banyaknya serangan hama putih palsu. $\mathrm{Hal}$ ini menunjukan kesimpulan dilapangan bahwa perlakuan B4 dan B3 sangat efektif untuk mengatasi serangan dari hama putih palsu. Perlakuan (B4 dan B3) hampir tidak terlihat adanya perbedaan.

\section{Intensitas Serangan Hama Penggerek Batang (Tryporiza sp.)}

Tabel 2. Intensitas serangan hama penggerek batang (Tryporiza sp.) pada tanaman padi (O. sativa)

\begin{tabular}{cc}
\hline \multirow{2}{*}{ Perlakuan } & Umur tanaman padi \\
\cline { 2 - 2 } & 11 minggu \\
\hline B0 & $\ldots \ldots \% \ldots \ldots$ \\
B1 & $11.78 \mathrm{c}$ \\
B2 & $10.81 \mathrm{~b}$ \\
B3 & $10.48 \mathrm{a}$ \\
B4 & $10.41 \mathrm{a}$ \\
\hline
\end{tabular}

Keterangan: Angka rata-rata yang diikuti oleh huruf yang sama menunjukkan tidak berbeda nyata menurut uji BNT pada taraf 5\% (BNT: $11 \mathrm{mst}=0,04)$.

Hasil pengamatan menunjukkan bahwa tanaman padi varietas Mekongga yang diuji menggunakan kombinasi jamur $B$. bassiana menunjukan hasil yang berbeda nyata. Hasil pengamatan ratarata intensitas serangan hama penggerek batang padi pada tanaman tiap perlakuan dapat dilihat pada Tabel 2. Berdasarkan hasil rata-rata serangan hama pada umur 11 mst, terlihat bahwa pengaplikasian jamur B. bassiana menunjukan hasil yang berbeda nyata terhadap setiap perlakuan. Pada perlakuan B4, B3, dan B2 tidak berbeda nyata dan pada perlakuan B0 berbeda nyata dengan semua perlakuan. Perlakuan B0 mempunyai intensitas serangan penggerek batang yang tertinggi kemudian diikuti dengan perlakuan B1, B2, B3, dan B4.

\section{Intensitas Serangan Hama Walang Sangit (Leptocorixa acuta Thunb).}

Tabel 3. Intensitas serangan (\%) hama walang sangit (L. acuta) pada tanaman padi (O.sativa)

\begin{tabular}{cccc}
\hline \multirow{2}{*}{ Perlakuan } & \multicolumn{3}{c}{ Umur tanaman padi } \\
\cline { 2 - 4 } & $10 \mathrm{mst}$ & $11 \mathrm{mst}$ & $12 \mathrm{mst}$ \\
\hline & $\ldots \ldots \ldots \ldots \ldots \ldots \ldots \ldots \ldots \ldots \ldots \ldots \ldots \ldots \ldots \ldots \ldots \ldots \ldots \ldots \ldots \ldots \ldots \ldots \ldots \ldots \ldots \ldots$ \\
B0 & $24.33 \mathrm{~d}$ & $21.12 \mathrm{~d}$ & $18.26 \mathrm{~d}$ \\
B2 & $21.20 \mathrm{c}$ & $19.26 \mathrm{c}$ & $15.80 \mathrm{c}$ \\
B3 & $13.87 \mathrm{~b}$ & $15.95 \mathrm{~b}$ & $13.11 \mathrm{~b}$ \\
B4 & $10.87 \mathrm{a}$ & $11.22 \mathrm{a}$ & $9.68 \mathrm{a}$ \\
& $10.32 \mathrm{a}$ & $10.76 \mathrm{a}$ & $9.68 \mathrm{a}$ \\
\hline
\end{tabular}

Keterangan: Angka rerata yang diikuti oleh huruf yang sama pada tiap kolom menunjukkan tidak berbeda nyata menurut uji BNT pada taraf 5\% $(\mathrm{BNT}$ : $10 \mathrm{mst}=0,13,11 \mathrm{mst}=0,16,12 \mathrm{mst}=0,12)$.

Hasil pengamatan menunjukkan bahwa tanaman padi varietas Mekongga yang diuji menggunakan kombinasi jamur B. bassiana menunjukkan hasil berbeda nyata menurut uji BNT. Hasil pengamatan rata-rata intensitas serangan 
hama walang sangit pada tanaman tiap perlakuan dapat dilihat pada Tabel 3 . Berdasarkan hasil rata-rata serangan hama pada minggu $10 \mathrm{mst}, 11 \mathrm{mst}$ dan 12 mst memberikan hasil yang berbeda nyata terhadap setiap perlakuan. Intensitas serangan tertinggi terdapat pada perlakuan B0 (kontrol) sedangkan intensitas serangan terendah terdapat pada perlakuan B3 dan B4, hal ini karena populasi walang sangit yang menyerang tanaman padi lebih sedikit.

Intensitas serangan tertinggi disebabkan oleh serangan hama Walang sangit, yaitu sebesar $24,33 \%$ pada minggu ke $10 \mathrm{Hal}$ ini bisa dimengerti karena ukuran tubuh hama Walang Sangit merupakan hama yang paling besar dibandingkan dengan ukuran tubuh hama lainnya yang menyerang pada pertanaman padi di Desa Sebuntal, Kecamatan Marang Kayu, Kabupaten Kutai Kartanegara (Sembiring, 2013). Disamping ukuran tubuhnya yang besar, Walang Sangit juga memiliki kemampuan makan yang tinggi. Ukuran tubuh Walang Sangit Walang sangit dewasa panjangnya bisa mencapai 14-17 mm dan lebar 3-4 mm (Wurjandari dkk., 2014), sementara kemampuan mengisap tanaman padi pada masa masak susu, dimana periode ini merupakan periode yang sangat enting dalam pembentukan bulir padi, sehingga serangan hama Walang Sangit akan menurunkan produksi tanaman padi (Syahta dkk., 2018). Penurunan produksi oleh hama Walang Sangit ini dapat mencapai 27\% (Poidatz et al., 2018). Efektivitas Beuveria lebih tinggi pada walang sangit, karena walang sangit merupakan hama yang hdupnya berada diluar tanaman, sehingga peluang walang sangit untuk kontak langsung dengan penyemprotan Beuveria menjadi lebih besar (Saranraj dan Javaprakash, 2017).

Berdasarkan hasil pengamatan diperoleh hama-hama pada pertanaman padi di lahan sawah Desa Sebuntal Kecamatan Marangkayu Kabupaten Kutai Kartanegara Provinsi Kalimantan Timur adalah hama Putih Palsu (Chanaphalocrosis medinalis) pada fase vegetatif, Penggerek Batang (Tryporiza $s p$.) pada fase generatif (beluk) dan hama Walang Sangit (Leptocorixa acuta Thunb.) pada fase generative (Sopialena, 2018). Hama-hama tersebut merupakan hama yang memang umum dijumpai pada pertanaman padi di Kalimantan Timur. Hal ini juga disebutkan oleh (Syahta dkk., 2018) bahwa hama-hama yang banyak terdapat pada pertanaman padi di wilayah Kalimantan Timur adalah Penggerek Batang (Tryporiza sp.), hama Putih Palsu (Chanaphalocrosis medinalis), Walang Sangit (Leptocorixa acuta Thunb).

B. bassiana memiliki kemampuan yang efektif dalam mengendalikan hamahama yang dijumpai di pertanaman padi di Persawahan Desa Sebuntal, Kecamatan Marang Kayu, Kabupaten Kutai Kartanegara, karena jamur ini memang memiliki kemampuan menginfeksi yang tinggi dalam mengendalikan hama. Hal ini sesuai dengan yang dinyatakan oleh (Sopialena dkk., 2018). Selain secara kontak, $B$. bassiana juga dapat menginfeksi serangga melalui inokulasi atau kontaminasi pakan (Widariyanto dkk., 2017).

\section{KESIMPULAN}

Berdasarkan hasil penelitian maka dapat disimpulkan bahwa terdapat 3 jenis hama serangga penting yang teridentifikasi di lahan sawah Desa Sebuntal Kecamatan Marangkayu Kabupaten Kutai Kartanegara Provinsi Kalimantan Timur, yaitu: hama Putih Palsu (C. medinalis) pada fase vegetatif, Penggerek Batang (Tryporiza sp.) pada fase generatif (beluk) dan hama walang 
sangit (L. acuta) pada fase generatif. Konsentrasi $B$. bassiana yang efektif dalam mengendalikan hama pada tanaman padi (O. sativa) adalah $15 \mathrm{gr} / \mathrm{L}$ air.

\section{DAFTAR PUSTAKA}

Kementerian Pertanian. (2014). Statistik Produksi Hortikultura Tahun 2014.

Dinas Tanaman Pangan dan Hortikultura. (2015). "Data Produksi Tanaman Padi Sawah di Kalimantan Timur Tahun 2011-2015". Samarinda, 2015.

Kartohardjono, A. (2011). Penggunaan musuh alami sebagai komponen pengendalian hama padi berbasis ekologi. Pengembangan Inovasi Pertanian, 4(1), 29-46.

Parsa, M., Dirgahayu, D. D., Manalu, J., Carolita, I., \& Harsanugraha, W. (2017). Uji Model Fase Pertumbuhan Padi Berbasis Citra Modis Multiwaktu Di Pulau Lombok (The Testing Of Phase Growth Rice Model Based On Multitemporal Modis In Lombok Island). Jurnal Penginderaan Jauh dan Pengolahan Data Citra Digital, 14(1).

Indiati, S. W., \& Marwoto, M. (2017). Penerapan Pengendalian Hama Terpadu (PHT) pada Tanaman Kedelai. Buletin Palawija, 15(2), 87-100.

Muhammad, A. (2015). Kelimpahan hama dan musuh alami pada pertanaman padi varietas pandanwangi di Kecamatan Warungkondang Kabupaten Cianjur. Departemen Proteksi Tanaman Fakultas Pertanian Institut Pertanian Bogor.
Usyati, N., Kurniawati, N., Ruskandar, A., \& Rumasa, O. (2018). Populasi Hama dan Musuh Alami pada Tiga Cara Budidaya Padi Sawah di Sukamandi. Agrikultura, 29(1), 3542.

Widariyanto, R., Pinem, M. I., \& Zahara, F. (2017). Patogenitas Beberapa Cendawan Entomopatogen (Lecanicillium lecanii, Metarhizium anisopliae, dan Beauveria bassiana) terhadap Aphis glycinespadaTanaman Kedelai: Pathogenicity of Some Entomophatogen's Fungus (Lecanicillium lecanii, Metarhizium anisopliae, and Beauveria bassiana) to Aphis glycines on Soybean. Jurnal Online Agroekoteknologi, 5(1), 8-16.

Sembiring, A. S. (2013). Sistem pakar diagnosa penyakit dan hama tanaman padi. Medan: STMIK Budi Darma, 3.

Agusdian, R., Rakhmadi, F. A., \& Widayanti, W. (2012). Sistem Proteksi Tanaman Padi Dari Serangan Hama Wereng Menggunakan Gelombang Ultrasonik Dan Penunjuk Arah Angin. In Seminar Nasional Fisika dan Pendidikan Fisika Ke-2 2012. Sebelas Maret University.

Syahta, R., Anggara, F., \& Jamaluddin, J. (2018). Alat Perangkap Hama Serangga Padi Sawah Menggunakan Cahaya dari Tenaga Surya. Journal of Applied Agricultural Science and Technology, 2(1), 11-19.

Poidatz, J., Plantey, R. L., \& Thiéry, D. (2018). Indigenous strains of Beauveria and Metharizium as potential biological control agents against the invasive hornet Vespa 
velutina. Journal of invertebrate pathology, 153, 180-185.

Saranraj, P., \& Javaprakash, A. (2017).

Agrobeneficial entomopathogenic fungi-Beauveria bassiana: A review. Indo-Asian Journal of Multidisciplinary Research, 3 (2),(2017), 1051-1087.
Sopialena, S. (2018). Pengendalian Hayati dengan memberdayakan potensi mikroba.

SOPIALENA, S., SUYADI, S., SAHIL, M., \& NURDIANA, J. (2018). The diversity of endophytic fungi associated with Piper nigrum in the tropical areas: A recent study from Kutai Kartanegara, Indonesia. Biodiversitas Journal of Biological Diversity, 19(6), 2028-2034. 